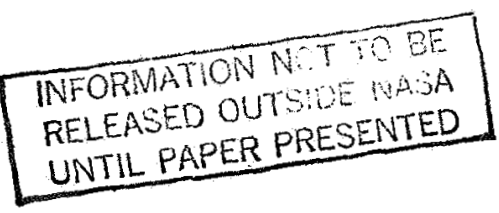

STRUCTIURAL PROSPECTS FOR HYPERSONIC AIR VHHICLES

By R. R. Heldenfels

NASA Iangley Research Center Langley Station, Hampton, Va.

Presented at the 5th Congress of the International Council of the Aeronautical Sciences (ICAS)

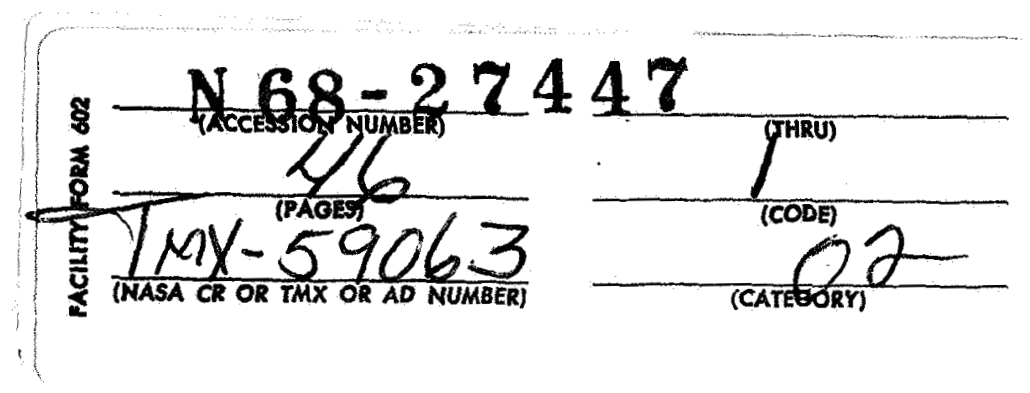

London, England

September 12-16, 1966

GPO PRICE \$

CFSTI PRICE(S) \$

Hard copy $(\mathrm{HC})$

Microfiche (MF) 


\section{STRUCTURAL PROSPECTS FOR HYPERSONIC AIR VEHICLES}

By R. R. Heldenfels*

NASA Langley Research Center

Langley Station, Hampton, Va.

\section{SUMMARY}

Proposed missions, configurations, and design requirements of hypersonic air vehicles with air-breathing propulsion are reviewed to determine the important structural design problems. High external surface temperatures and internal storage of cryogenic fuel in a vehicle with a structural weight fraction comparable to current subsonic aircraft put stringent requirements on the selection of materials and structural configurations. Structural configurations resulting from research on fuselage liquid hydrogen tankage, wings, heat shields, and air inlets are reviewed to indicate their applicability to a future hypersonic commercial air transport. It is concluded that substantial improvements in materials, structural concepts, and structural analysis are needed if hypersonic transportation is to become routine. A particularly important need is the fabrication of representative structural components for tests under appropriate environmental conditions to determine the adequacy of newly developed structures technology for hypersonic flight applications.

\section{INTRODUCTION}

With long-range air transportation a routine matter at subsonic speeds and supersonic operations expected in the near future, much aeronautical research is being devoted to hypersonic airplanes with air-breathing propulsion systems.

\footnotetext{
${ }^{*}$ Chief, Structures Research Division
} 
The unprecedented character of the design requirements of flight environment of such vehicles, however, presents the greatest technical challenge in the history of aeronautical research and development. If the hypersonic vehicle is to be successful, the structural designer must provide lightweight structures for a very large vehicle subjected to severe aerodynamic heating with structural efficiency approaching that of the best subsonic aircraft.

The types of missions and configurations proposed for hypersonic aircraft are shown in figure 1. In addition to the usual application's to transportation and military operations (strike, reconnaissance, defense, or logistics), the hypersonic airplane has been considered for the reusable first stage of a space launch system. A wide variety of vehicle configurations has been proposed for these missions, including lifting bódies, discrete wing-fuselage arrangements, and $a$ blend of the two. Propulsion units may be placed in external pods or blended into the body with the inlet in the wing compression field or wrapped around the fuselage. Each mission and configuration has its peculiar problems, but the major structural problems are common to all.

The purpose of this paper is to review the major structural design problems common to all hypersonic air vehicles and describe some of the current research results to indicate the structures and materials technology produced during the initial phase of a new era in aeronautics. To further limit the scope of the discussion and to focus it on a particular application, these structural problems will be discussed in relation to a hypersonic commerclal air transport that might be ready for intercontinental airline service 15 to 20 years hence. 
STRUCTURAT PROBLFM AREAS

The magnitude of the structural design problem of hypersonic commercial air transports is indicated by the structural weight ratios used in recent system studies. Such data are presented in figure 2 and compared with similar data for all types of long-range commercial air transports. The ratio of structural weight to gross weight at take-off is plotted as a function of vehicle cruising Mach number.

Subsonic commercial air transports (both propeller and jet types) have a structural weight ratio of approximately 25 percent. Supersonic transport designs are achieving about the same values despite expected decreases in structural efficiency because of aerodynamic heating. System optimization of supersonic transports has revealed combinations of vehicle sizes, configurations, structures, and materials that result in about the same structural weight ratios as subsonic transports. Studies of hypersonic airplanes, however, show somewhat higher structural weight ratios which seriously affect the economic feasibility of the vehicle. A structural weight ratio of 25 percent appears to be nearly an optimum value for long-range transports of a wide range of sizes and performance. Past advances in structures technology, therefore, are reflected in increased aircraft size and as improvements in the aerodynamic configuration rather than in reduced structural weight ratios.

The two factors responsible for the structural design problems and high structural weight ratios of hypersonic airplanes are (1) the high temperatures produced by aerodynamic heating and (2) the storage and use of liquid hydrogen fuel. Although the structural consequences of high temperatures are well known, they create new problems in this highly efficient, long-service-life aircraft. 
The Ilquid hydrogen causes novel aircraft design problems; it has been used as a fuel in only a few expendable space launch vehicles. These two factors have a profound influence on the structures, propulsion, and aerodynamics of the vehicle and lead to proportions and configurations quite different from those of lower speed aircraft. New challenges in all design disciplines require a greater interaction between members of the design team than ever before in aeronautics. The structural designer will have a greater influence on the size and configuration of the hypersonic airplane than for subsonic or supersonic aircraft.

Figure 3 shows several isotherms on a hypersonic air vehicle configuration assumed to be cruising at Mach 8 at 88,000 feet. Temperatures shown are those at which the radiation cooling of the surface is in equilibrium with the aerodynamic heating, the steady-state values expected during a typical flight of 1 to 2 hours duration. Inside the propulsion unit, however, the heat flux is very high and little radiation cooling is possible. Consequently, interior surfaces will reach the highest temperatures on the aircraft unless they are cooled.

Most of the vehicle surfaces attain temperatures at which metallic materials have lost much of their efficiency, and significant areas approach the melting point of the refractory metals. The temperatures can be controlled to some extent by variation of cruising speed and altitude, but flight efficiency demands that materials and structures technology be pushed to the maximum attainable temperature limits. Some nonmetallic materials, ablators for example, could be used for thermal protection but they have low efficiency in this application and must be replaced after each flight. Fxternal surfaces of metallic materials having a lifetime of many flights are preferred. 
Figure 4 shows some of the temperature limitations of metallic materials that influence structural design. Temperature is plotted as a function of total time exposed to that temperature, and typical limits are shown for two families of metals, the superalloys (nickel or cobalt base) and the refractory metals (molybdenum, columbium, tantalum, and tungsten). These limits were determined with arbitrary criteria for acceptable strength, stiffness, creep, and surface oxidation and are shown shaded to indicate that they are inexact. Only the better alloys in each family were considered in establishing these limits. The strength limit is defined as the temperature at which the tensile strength-todensity ratio is one-half the room temperature value. A similar criterion is used for the stiffness (modulus of elasticity) limit. The creep limit allows 1 percent creep at a stress-density ratio of one-fourth that for the strength limit at the same temperature. (Note that some of these limits approximately coincide and are not identified separately.) A weight change equivalent to a loss of 0.001 inch of material is the oxidation limit. These are highly simplified criteria, but illustrate the primary character of a very complex materials selection problem.

The superalloys have good load-carrying ability up to about $1600^{\circ} \mathrm{F}$ and the refractory metals retain much of their strength to about $2400^{\circ} \mathrm{F}$. Both can be used in less demanding applications at higher temperatures, the refractory metals having acceptable stiffness to temperatures above $3000^{\circ} \mathrm{F}$. The most significant limit, however, is that imposed by oxidation. The superalloys generally are considered to be highly oxidation resistant but they experience serious deterioration from oxidation at about the same temperatures and times at which they experience a large loss of strength. The refractory metals are well known for their rapid oxidation and cannot be used without a protective 
coating. Coating technology, however, has not advanced sufficiently, despite years of research and development, to assure long life for refractory metal structures at the high temperatures where their mechanical properties exceed those of all other metals.

These material limitations, then, indicate that superalloys are suitable for construction of hot load-carrying structures at temperatures up to about $1600^{\circ} \mathrm{F}$ and, hopefully, will be serviceable for the economic life of the aircraft. Iittle data are available, however, at exposure times longer than 1000 hours so that prediction of their behavior for the expected life of a hypersonic commercial air transport is not possible at present. Those parts of the aircraft that operate at higher temperatures, whether of superalloys or refractory metals, must be periodically replaced or refurbished. Refractory metal components should be used only to the extent that no other material or design approach will assure the success of the vehicle.

Many other material considerations influence the structural design of hypersonic aircraft but only a brief indication of their scope will be presented. Good fabrication characteristics such as forming, machining, joining, welding, and brazing are essential. Fatigue from cyclic loads and fracture characteristics will be important at low and moderate temperatures during climb, descent, and landing but may be insignificant during the high-temperature cruise. Another significant factor may be thermal fatigue due to the once-perflight heating cycle. Embrittlement by hydrogen, oxygen, or other substances may be a major factor. Stress corrosion problems have been a cause for concern in the selection of materials for supersonic transports and spacecraft and also may be important for hypersonic air vehicles. 
The numerous structural problems of hypersonic air vehicles will be reviewed with the aid of figure 5 which identifies the critical components. Many new problems are associated with the storage and use of hydrogen fuel which is essential for achieving a reasonable cruising range at hypersonic speeds. It has a low density and a large fuel storage volume is required. (A volume of liquid hydrogen four times that of the usual hydrocarbon fuels is required to obtain the same energy content; however, the liquid hydrogen weighs less than one-half as much.) The problem is complicated further by storing: this cryogenic liquid in a vehicle subjected to severe heating and the potential hazards of operating a man-carrying vehicle containing hydrogen.

The location of the liquid hydrogen tank is a major design consideration. Analyses show that storing all the liquid hydrogen in the fuselage, where favorable surface-to-volume ratios are obtainable, is more attractive from a weight comparison than storage in the available spaces in the wing, particularly for the discrete wing and body configurations shown here. The fuselage (containing liquid hydrogen tankage) will be the heaviest structural component of the vehicle, thus much effort to devise feasible lightweight solutions is justified. (The heaviest component of subsonic and supersonic transports is usually the wing.) The passenger, cargo, and crew compartments present similar problems, but they should be less critical because they probably require a smaller volume and a lower unit thermal protection weight than for the fuel tanks.

The wing structure, second heaviest component, also requires a lightweight approach and a hot load-carrying configuration appears attractive. Some areas, where the temperature exceeds the strength limit of the material, will require insulation and heat shields. The heat shield will be divided into small panels 
to minimize thermal stresses. The lightest. skin panels for both the heat shields and hot primary structure may have rougher surfaces than desirable aerodynamically. Structural approaches developed for the wing are applicable to the control and tail surfaces. Controls occupy a small portion of the vehicle surface and occasional replacement of components may be acceptable.

Very special structural and material approaches are required in the hottest areas (nose tip and the leading edges of the inlet, wing, and tail). Graphites, ceramics, or refractory metals will be required to withstand the high temperature and segmented designs may be used for thermal stress relief. Fortunately, these components cover only a small part of the vehicle surface and much technology applicable to these areas has been developed in entry vehicle programs, particularly the X-20 (Dynasoar) and ASSEI vehicles of the U.S. Air Force. Thus, replaceable but feasible structures of high unit weights and short lives can be built for these portions of the vehicle.

The propulsion unit and its structure experience particularly high heating and loading and require structural cooling to survive. The hydrogen fuel is an excellent coolant and can be used. The use of fuel for structural cooling, however, is a major innovation in aircraft design.

A typical hypersonic air vehicle, therefore, will employ one or more versions of all the basic approaches to high-temperature structures (hot, insulated, or cooled) and a wide variety of structural materials. Some structural concepts that have closely spaced joints and general surface roughness may create undesirable flow disturbances and provide another design interaction between structures and aerodynamics. A number of structural concepts proposed for solving the principal structural problems of the major components (fuselage liquid hydrogen tankage, wing structure, heat shields, and propulsion-system 
structure) will be described in more detail in the following pages to indicate the status of current research and the degree of creativity required in the future.

\section{STRUCTURAI CONCEPTS}

Fuselage Liquid Hydrogen Tankage

Two general concepts for storing liquid hydrogen in the fuselage of a hypersonic vehicle are shown in figure 6 . The sketch at the top illustrates how hydrogen tanks may be located in the fuselage along with passengers, cargo, and crew. At the bottom are shown typical arrangements for integral and nonintegral tankage. In the integral system, the structure also forms the tank wall. To prevent excessive boil-off of liquid hydrogen (at $-423^{\circ} \mathrm{F}$ ) during flight, the tank wall must be insulated from the high surface temperature. A secondary structure in the form of metallic heat shields provides the aerodynamic surface and protects the lightwelght insulation from the external airflow. In the nonintegral approach, the tanks are suspended within the structure and insulated from it, the structure providing the heat shield for the insulation. With either approach, a barrier is required between the external surface and the insulation to prevent cryopumping of air to the tank wall (which could lead to excessive fuel boil-off and large ice deposits in the insulation) when the vehicle is on the ground or in flight. This barrier can be formed by the purge gas shown in the figure or by sealing the outer surface of the insulation.

When the tank is wetted by Iiquid hydrogen, it is at a temperature of $-423^{\circ} \mathrm{F}$, but as fuel is consumed, the dry portion of the wall may reach tem-

peratures as high as $1000^{\circ} \mathrm{F}$, creating large temperature differences, and thermal stresses, in the tank. This problem could seriously degrade the 
load-carrying ability of the integral tank approach unless some type of system is provided to keep all of the wall wet.

Studies of integral tankage show that current concepts have numerous problems in structural arrangement and fabrication and the present state of the art does not provide a weight advantage over the nonintegral approach. Current research and development, therefore, is devoted primarily to assessing the weight penalties associated with thermal protection systems for nonintegral tanks.

Thermal protection system weights for four types of nonintegral tankage, for which much analysis and some experimental verification have been accomplished, are compared in figure 7. Comparisons are made here for a 1.5-hour flight time at an average surface temperature of $1500^{\circ} \mathrm{F}$ and with a purge gas pressure of 1 psia. Fach concept shown includes the same hot load-carrying structure and separate tank wall so that only the weights chargeable to thermal protection are compared. The total weight of insulation, fuel bolled off, and other items has been minimized to determine the optimum combinations. The weight breakdown for each system is shown with the weight of purge gas, $\mathrm{CO}_{2}$ frost, manifolds, gas tanks, and accessories totaled in the "other" column. The first system uses helium gas as the purge because of its low liquefaction temperature $\left(-452^{\circ} \mathrm{F}\right)$. The high conductivity of the helium at a purge gas pressure of 1 psia leads to very thick insulation and large fuel losses, resulting in a high system weight. The next two systems employ sealed insulation, one is a cryoevacuated plastic foam sealed in a plastic film and the other is an evacuated metallic foil insulation sealed with a welded cover skin. These systems offer potential weight saving over the helium purge system, but considerable difficulties have been encountered in manufacturing and maintaining 
an adequate seal. These systems are beyond the state of the art at present but future development may make them more attractive.

The fourth system is a carbon dioxide frost and purge concept developed from research at the NASA Langley Research Center. During a ground hold before each flight, the frost is cryodeposited, from a mixture of helium and carbon dioxide purge gas, within the inner layers of the fibrous insulation on the tank walls. After the aircraft takes off, the frost sublimes, initially as the result of reduced pressure with increased altitude and then by aerodynamic heating. Sublimation of the $\mathrm{CO}_{2}$ provides a continuous supply of purge gas which flows outward through the insulation and lightly pressurizes the purge space, thereby preventing cryopumping of air through the unsealed structure. Carbon dioxide was selected because its low thermal conductivity gives good insulation efficiency and its lack of a liquid phase prevents erratic performance from liquid flowing down the tank sides. The heat absorption capability of the subliming frost and the transpiring gas also contributes to the effectiveness of the insulation.

Pure carbon dioxide will cryodeposit on a liquid hydrogen tank as a clear ice with a density of about 104 pounds per cubic foot, much too dense for this application. However, when introduced with a noncondensable gas (helium), much lower densities are achievable. A frost density of 25 pounds per cubic foot is recommended for best results. Experiments have established means for controlling frost density during deposition and analyses predict that adequate frost thickness can be obtained on the ground prior to flight in as little as 2 hours. Deposition of the optimum frost thickness, however, requires a somewhat longer time. 
The carbon dioxide system, with a weight of less than 2 pounds per square foot, offers a weight saving of 3 pounds per square foot over the only other system that can operate successfully at present. This difference in required thermal protection weight between the carbon dioxide and helium systems, when integrated over the large fuel tank surface, is comparable to the payload weight of proposed hypersonic commercial air transports. Thus, weight savings in the hydrogen tankage can be extremely important.

The total unit weight of the tankage section of the fuselage structure will be the thermal protection weight shown in figure 7 plus the weight of the load-carrying structure and tank wall. They may add as much as 4 pounds per square foot, making the total unit welght of the systems analyzed range from 6 to 9 pounds per square foot.

A test model of the $\mathrm{CO}_{2}$ system has been constructed and is now being prepared for test at the NASA Langley Research Center. The components and the assembled model are shown in figure 8. It consists of a superalloy structure of Z-stiffened skin panels and a separate insulated tank of aluminum alloy with waffle grid stiffening. The tank is suspended within the structure by corrugated skirts at each end. With a fully developed $\mathrm{CO}_{2}$ frost layer, this model weighs 6 pounds per square foot. The structural configuration employed in this model can be built with state-of-the-art fabrication techniques. However, a simplified technique for assembling the Z-stiffened panels reduced the cost of fabrication and a simple reusable seal was developed for joints in the cryogenic tanks. This seal consists of a flat Teflon gasket between flanges connected by closely spaced fasteners; it has a satisfactorily low leakage rate. The concepts previously discussed of nonintegral tankage may be adequate for a feasible hypersonic air vehicle, but further improvements in hydrogen 
tank structures are both necessary and possible. Figure 9 shows an integral tank concept resulting from research at the NASA Langley Research Center. It is called multiwall construction because a multitude of flat and dimpled metalIic sheets are used to provide the structure, insulation, and tank wall in a single integrated component. The details of the configuration are shown in the sketch and the complete model is shown in the photograph. The inner layers of the multiwall sandwich are of titanium alloy and the outer layers are of nickelbase superalloy. The inner layers are thicker and serve as primary structure while the multiple outer layers serve as insulation and are bf minimum gage construction. The inner layer can be pressurized with helium to provide a leak detection system and prevent the outward flow of hydrogen gas. This concept requires leak-tight construction (at the outer heat-shield surface and at both layers of the load-carrying structure) and therefore is difficult to fabricate. Although the fabrication of this multiwall model was somewhat less than successful, a number of useful process developments occurred. Techniques were developed for polishing metal foils ( 0.002 to 0.018 inch thick) to obtain low emittance and thus improve the insulating ability of the multiwall. Methods were developed also for dimpling sheets of metal foil and welding foils of the various alloys used in the model. Problems encountered in foil gage welding were high residual stresses that caused tension fallure in longitudinal seams between panels and leakage through welds. The thinnest foil used for sealed surfaces was 0.008 inch thick and hundreds of leaks were present. Many leaks were found and repaired; but repairs created new leaks with the result that a vacuum-tight insulation was never obtained. In the photograph, the numerous welds are evident and some of the fabrication problems are obvious. The total weight of tank, structure, and insulation in this model is about 4 pounds per 
square foot. The model with the carbon dioxide system (fig. 9) weighs about 6 pounds per square foot with about two-thirds $\left(4 \mathrm{lb} / \mathrm{ft}^{2}\right)$ of the weight in the separate tank and Z-stiffened hot structure. The low weight potential of the multiwall concept, with its integral sandwich-type tank and structure, therefore warrants additional effort in the development of reliable means for leakfree joining of metals in foil gages.

The models shown in figures 8 and 9 will be laboratory tested under simulated environmental conditions by application of loads and radiant heating with cryogenic liquids in the tank. Following these tests the models will be tested at Mach 7 in a large true-temperature hypersonic wind tunnel at the NASA Langley Research Center. These tests should provide considerable insight into the fuselage tankage problems of hypersonic aircraft and provide a basis for more accurate predictions of the unit weights required.

\section{Wing Structures}

The wing of the hypersonic airplane will be a large surface with low loads in the skin panels. A hot load-carrying type primary structure will probably have the least weight. It will be a dry wing because the insulation problems of liquid hydrogen tanks produce severe weight penalties in the inefficient wing volumes available. One prospective wing structural concept is shown in figure 10. The schematic on the left shows the entire wing, the other sketches show the details. A one-piece structure extending from wing tip to wing tip, consisting of an array of ribs and spars connected by skin panels, is shown. A minimum-weight carry-through structure under the pressure vessels in the fuselage is provided by this arrangement. The structure should be simple to fabricate, light in weight, present a smooth surface to the external airflow, and 
encounter low thermal stresses due to wing-fuselage interaction and to temperature differences in the wing itself. Thermal stress due to temperature differences within the spars and ribs can be alleviated by using corrugated webs. In the configuration illustrated, the spar and rib caps are exposed directly to the aerodynamic heating to reduce temperature differences between the caps and skin panels. A waffle configuration skin panel is shown, providing a smooth aerodynamic surface and good radiant heating interchange between the upper and lower wing surfaces to help equalize their temperatures. However, many other panel configurations can be used here.

The relative weights of nine of the many possible skin panel configurations are shown in figure 11 for a unidirectional compressive load index of $1 \times 10^{-6}$ on a square panel. This structural index is the panel buckling load (P) divided by the panel width (b) squared and the modulus of elasticity of the material (E). This value of the index is representative of a hypersonic wing structure in which compression panels buckle elastically. Weights are given relative to that of the honeycomb-core sandwich which is often, but incorrectIy, considered to be the most efficient arrangement. Configurations range from unstiffened skin to combinations of contoured sheets and differ in weight by more than an order of magnitude. The interesting stiffened configurations, however, encompass only a factor of 3 in weight differences. Two configurations employing judicious placement of material weigh less than the honeycomb-core sandwich. The lightest panel consists of a corrugation with beaded webs that provides a deep panel with high moment of inertia without local buckling or foil-gage problems. Cap strips are added to provide additional load-carrying material at the extreme fibers. This panel requires only a single layer of material, and thus is inherently lighter than multisheet 
concepts when minimum skin thickness limits are encountered, a frequent occurrence in hypersonic aircraft structures. Additional study may reveal even lighter panel concepts.

In minimum gage superalloy materials, the beaded corrugation and the single corrugation can be constructed with weights less than 1 pound per square foot; however, they are unsuitable for areas in which the air flows directly over the surface. Then, other solutions such as the beaded skin, the Z-stiffened panel, and waffle grid are favored. The relative ability of these panels to carry transverse compressive loads is also important in biaxially stressed delta wings. The waffle grid is an attractive configuration with a smooth surface, it has good load-carrying ability in all directions, but it weighs more than the other configurations. The beaded skin provides high efficiency but its load-carrying ability is unidirectional and aerodynamic and heating penalties may result from its slight surface roughness. The honeycomb sandwich has none of these problems, but it is difficult to fabricate and is unattractive in minimum gage situations. The Z-stiffened panel is a simple, state-of-the-art configuration with a smooth surface and a moderate weight penalty compared to the honeycomb sandwich. It is attractive for carrying unidirectional loadings (fuselage structure, for example) but its use in a delta wing may result in a greater total wing weight than use of the heavier waffle panel.

The final details of the wing structure will be determined by combined optimization of the rib and spar spacing and skin panel configuration, including the effects of thermal stresses as well as the applied air loads. Such studies indicate that a closer spacing of ribs and a somewhat larger spacing of spars 
should be used when thermal stresses are present due to fuselage restraint of the thermal bending of the nonuniformly heated wing.

In addition to the hot $\left(<1600^{\circ} \mathrm{F}\right)$ primary load-carrying structure of the wing, required components are heat shields on lower surface areas that exceed $1600^{\circ} \mathrm{F}$, leading edges, and control surfaces. The heat shield covered structure and the leading edge might be a secondary structural component separate from the primary structure if the $1600^{\circ} \mathrm{F}$ design isotherm is located forward of the 25 percent chord line. On higher performance aircraft, a more complicated integration of shielded and unshielded primary structure is required, using concepts described in the next section.

\section{Heat Shields}

On those areas of the vehicle where integral tankage is used or where the temperature limits of a hot load-carrying structure are exceeded, the structure must be protected by insulation. The extent of such areas is dependent on the design speed and altitude. Figure 12 shows an arrangement which might be used on the lower surface of the wing near the leading edge or on the lower, forward fuselage (fig. 5). (The lower wing surface is the top of the sketch in fig. 12.) Insulations with attractive values of the product of conductivity and density $(k \rho)$ are too flimsy to survive exposure to the airstream and require a protective cover (heat shields).

The insulation layer is thick enough to keep the temperature of the loadcarrying structure from exceeding design limits. The load-carrying structure illustrated is the highly efficient beaded corrugation (fig. 1l). If constructed of superalloys with a high-temperature limit, the required weight of insulation will be reduced and compatibility will be maintained with the 
unshielded structure farther aft. The weight of insulation and heat shield decreases the structural efficiency of this arrangement, consequently this approach should be used only when no other is feasible.

A low-temperature, light-alloy structure can be used inside the heat shield and insulation. However, the additional weight of insulation, and possibly of a cooling system, will probably override any weight savings that accrue from the increased structural efficiency provided by the low-density, low-temperature material.

The heat shield may be constructed of a superalloy $\left(<2200^{\circ} \mathrm{F}\right)$ or a refractory metal $\left(<3100^{\circ} \mathrm{F}\right)$, depending on the design temperature. The coated refractory metal heat shield illustrated is of corrugated skin construction that carries only transient pressure loads to the substructure. This panel is shaped and supported such that thermal stresses are minimized. Note that the corrugations in the heat shield run perpendicular to the spars, approximately in the streamwise direction. The "streamwise" orientation, however, does not eliminate flow disturbances and increased local heating because cross flows can be expected on hypersonic aircraft configurations. Smoother surfaces are possible, with honeycomb sandwich heat shields, for example, but probably involve a weight penalty since heat shields are usually of "minimum gage" construction with single sheet concepts being lighter. The conflicting desires of aerodynamics and structures relative to surface smoothness in this and other areas present opportunities for interdisciplinary trade-off in vehicle design optimization.

Research and development on heat shields has been in progress for over a decade with emphasis, until recently, on entry vehicle applications. Metallic heat shields (superalloy and refractory) have been flown successfully on 
Mercury, Gemini, and ASSEI flights and were a vital part of the structure designed for the X-20 (Dynasoar). Figure 13 is a photograph of a heat shield constructed of 0.008 -inch-thick tantalum alloy (10-percent tungsten) prior to application of an aluminide (tin-aluminum-molybdenum) coating. After coating, the parts shown weighed 1.7 pounds per square foot, a value that probably could be reduced by additional design refinements. Coating the panel increased its weight over 20 percent, a significant penalty to add to that resulting from the high weight per unit area of foil-gage refractory metals. (One square foot of sheet 0.010 inch thick ranges in weight from 0.10 pound in magnesium to 1.0 pound in tungsten. The heat shield of fig. 13 would weigh about 0.8 pound per square foot if made of an uncoated superalloy.) Note that special attention has been given to details of the attachments so that all areas of the refractory metal can be adequately coated and protected from oxidation. Coupon tests of this coated material in both static and dynamic cyclic oxidation tests produced coating failures in about the time-temperature combinations shown for coated refractory metals in figure 4.

\section{Propulsion System Structures}

A simple schematic of the propulsion unit of a hypersonic airplane and a potential structural concept is shown in figure 14. The unit consists of a two-dimensional inlet and a turbo-ramjet engine for use up to Mach numbers of

about 6. Supersonic-combustion ramjets (scramjets) must be developed for operation at higher speeds. For the subsonic combustion engine illustrated, the inlet flow is compressed to high pressure and high temperatures with an additional temperature increase occurring in the engine combustor. Pressures up to 250 psi and heat fluxes up to 500 Btu per square foot per second may be experienced. If a scramjet is used, the pressure and heat flux within the system may 
be somewhat lower but still severe enough to present a major problem. Regardless of the propulsion system used, the internal surfaces cannot be cooled by radiation, which is so beneficial on the exterior, and an actively cooled structure like that shown in the lower half of figure 14 is required to solve the structural and thermal protection problems. Hydrogen is a very efficient coolant (high heat-sink capacity) and it is onboard the vehicle as fuel. If the coolant requirements for the structure are less than the fuel requirements for propulsion, the weight penalty for active cooling is small. However, general structural cooling of the aircraft is unlikely since the coolant required for the propulsion unit alone may equal the fuel required for propulsion at Mach numbers as low as 7 .

The interior wall of the air inlet is a heat exchanger through which hydrogen gas flows. A manifold system brings pressurized hydrogen from the tanks to the surface heat exchangers, where its temperature is increased to about $1500^{\circ} \mathrm{F}$ (without a phase change), and then feeds it to the combustion chambers. In the concept shown, the heat exchanger is not a part of the loadcarrying structure of the interior inlet wall, but integral arrangements are possible. External surfaces of the propulsion unit can use structural approaches similar to those previously discussed for the wing, but cooling may be necessary on and near the sharp inlet leading edges.

Figure 15 shows three concepts of hydrogen cooled structures and compares them on a unit weight basis for a range of heating and loading conditions. An allowance for manifolds, plumbing, and pressure seals between panels has been included. These concepts range from integration of heat exchanger and structure to complete separation of these functions. The pressures and heating rates cover the values expected for both external surfaces of the aircraft and 
internal parts of high-pressure inlets and combustion chambers. The integral system on the left is the lowest weight approach for low pressures and low heating rates, but unattractive for the more severe conditions in an inlet. The system with the heat exchanger separated from the structure but bonded to it (center) is usable throughout the range of conditions studied but it is too heavy for the severest environment. The system which involves two levels of heat exchange and a separate cold structure (right) has an increasing weight advantage as the environment becomes more severe. These results are based on the assumption that the structure is not significantly heated from the lower side; this could be a particularly important consideration for the cold structure on the right.

The concepts described are the product of comprehensive analytical studies that must be verified by experiments. Structural optimization of cooled structures involves the usual problems of configuration and material selection plus consideration of coolant pressure, passage geometry, flow routing, distribution, manifoloing, and coolant economy. Material selection is a major problem for the heat exchanger elements which, for the optimum passage geometry, are designed by internal pressure but their service life is determined by thermal fatigue from the high thermal stress cycle that occurs on each flight. In addition, strength at elevated temperature, oxidation resistance, creep strength, and hydrogen compatibility are important considerations. Some of the superalloys appear to be satisfactory materials for this application.

The fabrication of the heat exchanger presents numerous problems and opportunities for technological advances. Optimum configurations result in the very tiny coolant passages (typical depths are less than 0.10 inch with 10 to 40 fins per inch) shown in figure 16 requiring fabrication of complex shapes of 
minimum gage materials. In addition, the influence of fabrication processes (brazing, welding, and heat treatment) on the properties of thin gage superalloys is an important consideration in heat exchanger design.

CONCLUDING REMARKS

From the foregoing discussion, it is evident that numerous structural concepts have been devised for hypersonic air vehicles but additional innovations and improvements are needed. If the current state of the art is used to solve the structural problems of figure 5, the approaches summarized in the next paragraph will be used. Future research may, however, invalidate many of these remarks.

The liquid hydrogen fuel will be stored in the fuselage along with the passengers and crew, the fuselage and tanks being the heaviest structural component. Nonintegral tanks with a carbon dioxide frost and gas purge thermal protection system are preferred, but advances in foil-gage welding technology could lead to more efficient integral tankage structures. Both the fuselage and wing will be hot-load-carrying superalloy structures, with those portions on the lower surface which experience temperatures above about $1600^{\circ} \mathrm{F}$ protected by a nonstructural superalloy or coated refractory metal heat shield system. The nose tip and wing leading edges will be fabricated of refractory metals or ceramics and frequently replaced. A leading edge, segmented to allow for thermal expansion, probably will be required, creating certain flow disturbances not present on lower speed aircraft. The optimum structure for the vehicle may have a somewhat rougher surface than desired from the aerodynamic viewpoint. Internal surfaces of the air induction system and propulsion unit will be cooled by the hydrogen fuel but it is unlikely that sufficient hydrogen 
will be available to cool other structural components. Unless substantial improvements are made in coating life, the use of refractory-metal components should be minimized, even at the expense of reduced vehicle performance. High-temperature structures technology has been accruing for more than a decade from the development of missiles and entry vehicles, but specific applications to hypersonic aircraft structures are just beginning to emerge. This technology, however, is not sufficient for the successful development of operational hypersonic air transports as indicated in figure 2. The structural weight fractions needed for effective hypersonic air vehicles will be obtained only if future research provides:

(1) New materials and new structural concepts, substantially better than now available, for the construction of lightweight high-temperature structures for wings and for fuselages containing cryogenic fuel

(2) Accurate analytical predictions of minimum weight structural concepts that can survive severe environmental conditions for trade-off studies of aerodynamics, propulsion, and structures

(3) Experimental verification of new analytical methods, new materials and new structural concepts in appropriate environmental conditions. Trade-off studies will establish optimum proportions and configurations of hypersonic aircraft which will be influenced more by advances in structures and materials technology than lower speed aircraft. Experimental research and development, particularly, is essential to establish early confidence in the newly developed technology and to reveal any unanticipated problems. Hopefully, the innovations required to achieve these goals will not exceed our capabilities. Several projects directed toward these objectives, under way in the United States by the National Aeronautics and Space Administration, have 
been noted and some of the resulting hardware illustrated. Similar work is being done by the U.S. Department of Defense. 


\section{ACKNOWLEHDGMERTI}

The author wishes to recognize the contributions of his colleagues in the Structures Research Division of the NASA Langley Research Center who created much of the advanced technology described herein. 


\section{BIBLIOGRAPHY}

1. Petersen, Richard H.; Gregory, Thomas J.; and Smith, Cynthia I.: Some Comparisons of Turboramjet-Powered Hypersonic Aircraft for Cruise and Boost Missions. ATAA Paper No. 65-759, Nov. 1965.

2. Gregory, Thomas J.; Petersen, Richard H.; and Wyss, John A.: Performance Trade-Offs and Research Problems for Hypersonic Transports. AIAA Paper No. 64-605, Aug. 1964.

3. Weber, Richard J.: Propulsion for Hypersonic Transport Aircraft. Proceedings of the $4 \mathrm{th}$ Congress of the International Council of the Aeronautical Sciences, Robert R. Dexter, ed., Spartan Books, Inc., 1965, pp. 977-999.

4. Brewer, G. Daniel: Manned Hypersonic Vehicles. Iockheed Horizons, Issue 4, First Quarter 1966, pp. 16-23.

5. Kelly, Donald L.: Reusable Aerospace Transports. Lockheed Horizons, Issue 4, First Quarter 1966, pp. 2-15.

6. Jackson, I. Robert; Davis, John G., Jr.; and Wichorek, Gregory R.: Structural Concepts for Hydrogen-Fueled Hypersonic Airplanes. NASA TN D-3162, 1966.

7. Childers, Milford G.: Structures and Materials for Hypersonic Vehicles. Lockheed Horizons, Issue 4, First Quarter 1966, pp. 24-37.

8. Mathauser, Eldon E.: Research, Design Considerations, and Technological Problems for Winged Aerospace Vehicles. Proceedings of the NASAUniversity Conference on the Science and Technology of Space Exploration, vol. 2, NASA SP-11, 1962, pp. 499-510. (Also available as NASA SP-28.) 
9. Pride, Richard A.; Royster, Dick M.; and Helms, Bobbie F.: Design, Tests, and Analysis of a Hot Structure for Lifting Reentry Vehicles. NASA TN D-2186, April 1964.

10. Wichorek, Gregory R.; and Stein, Bland A.: Experimental Investigation of Insulating Refractory-Metal Heat-Shield Panels. NASA TN D-1861, Dec. 1964.

11. Lisagor, W. Barry; and Stein; Bland A.: A Study of Several OxidationResistant Coatings on $\mathrm{Cb}-10 \mathrm{Ti}-5 \mathrm{Zr}$ Alloy sheet at $2000^{\circ} \mathrm{F}, 2400^{\circ} \mathrm{F}$, and $2700^{\circ} \mathrm{F}\left(1365^{\circ} \mathrm{K}, 1590^{\circ} \mathrm{K}\right.$, and $\left.1755^{\circ} \mathrm{K}\right)$. NASA TN D-3275, 1966.

12. Scott, Russe1l Burton: Cryogenic Engineering. D. Van Nostrand Co., Inc., 1959.

13. Jackson, I. Robert; and Anderson, Melvin S.: A Carbon Dioxide Purge and Thermal Protection System for Iiquid Hydrogen Tanks of Hypersonic Airplanes. Paper presented at the 1966 Cryogenic Engineering Conference, Boulder, Colorado, June 13-15, 1966.

14. Heathman, John H.; and Kelly, Larry G.: Hydrogen Tankage for Hypersonic Cruise Vehicles. A Volume of Technical Papers presented at ATAA/ASME Seventh Structures and Materials Conference, Cocoa Beach, Florida, April 18-20, 1966, pp. 430-438. 
IIST OF FIGURES

Figure 1.- Missions and configurations of hypersonic air vehicles with airbreathing propulsion.

Figure 2.- Structural weight ratio trends for long-range commercial air transports.

Figure 3.- Equilibrium surface temperatures during sustained flight at Mach 8 at 88,000 feet.

Figure 4.- High-temperature structural material limitations.

Figure 5.- Structural problem areas of hypersonic commercial air transports.

Figure 6.- Structural concepts for liquid hydrogen tankage.

Figure 7.- Thermal protection system weights for nonintegral liquid hydrogen tanks ( 1.5 hours at $1500^{\circ} \mathrm{F}$ surface temperature).

Figure 8.- Hot structure and nonintegral liquid hydrogen tank with carbon dioxide purge and frost system.

Figure 9.- Multiwall structure and tank for liquid hydrogen.

Figure 10.- General arrangement and details of wing structure.

Figure 11.- Relative weights of square compression panels at a structural index of $\mathrm{P} / \mathrm{EHO}^{2}=1 \times 10^{-6}$.

Figure 12.- Insulated wing structure for surface temperatures greater than $1600^{\circ} \mathrm{F}$.

Figure 13. - Tantalum alloy (Ta-10W) heat shield.

Figure 14.- Two-dimensional air inlet propulsion system and structural concept.

Figure 15.- Structural concepts and relative weights for hydrogen-cooled structures.

Figure 16. - Typical hydrogen heat exchanger. 


\section{COMMERCIAL TRANSPORTATION$$
M=6-8
$$

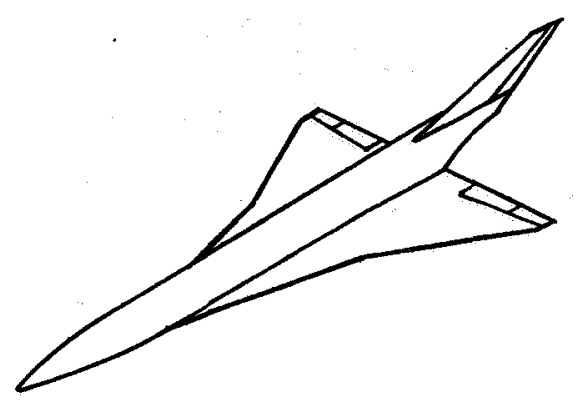

SPACECRAFT LAUNCHING

$$
M=3-12
$$

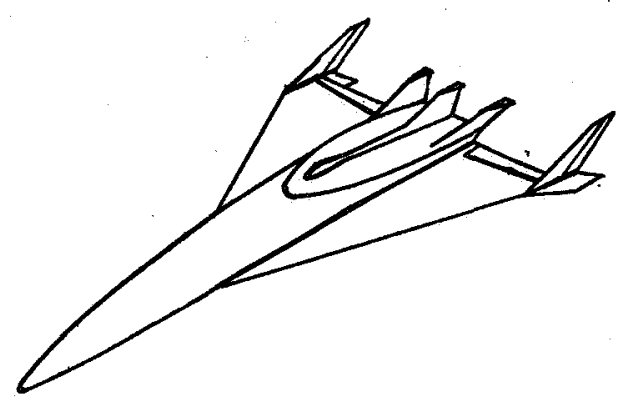

MILITARY OPERATIONS

$$
M=8-12
$$

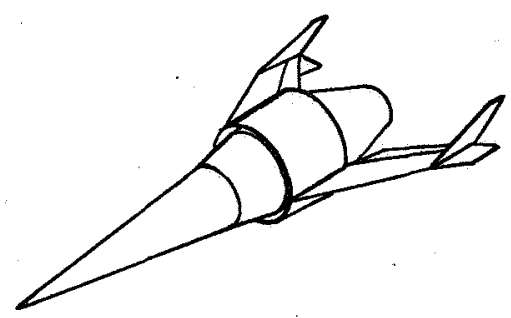

Figure 1.- Missions and configurations of hypersonic air vehicles with air-breathing propulsion. 


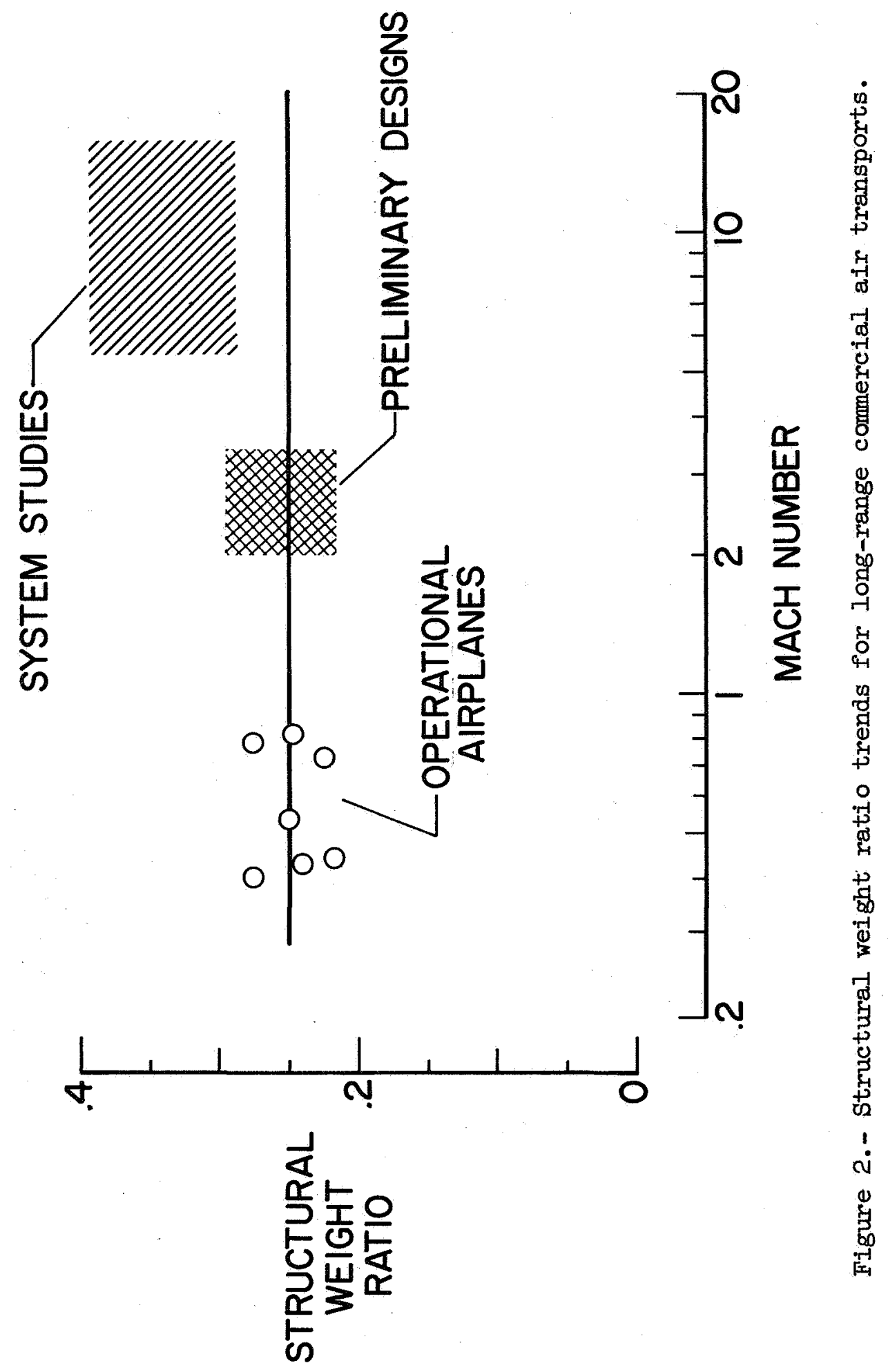




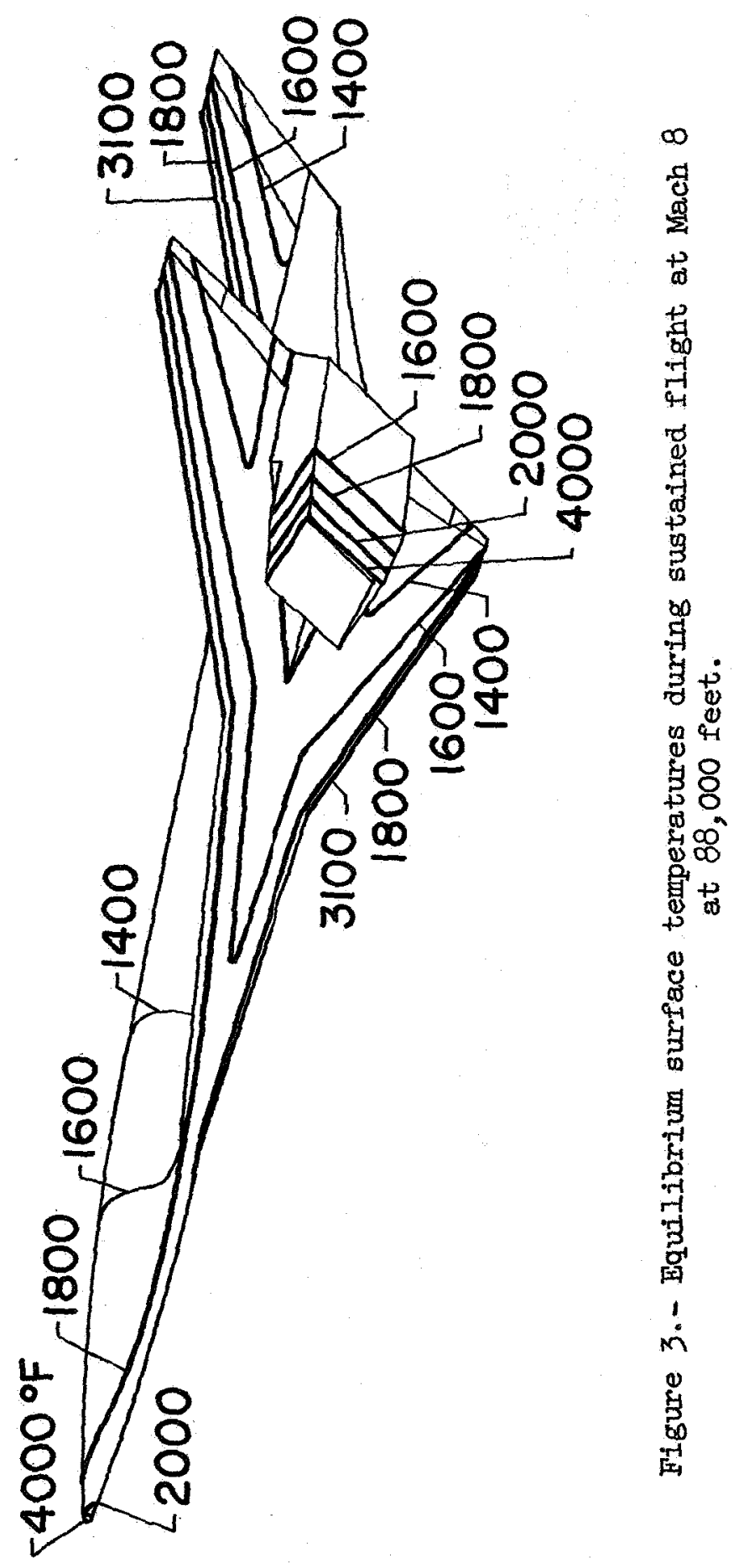




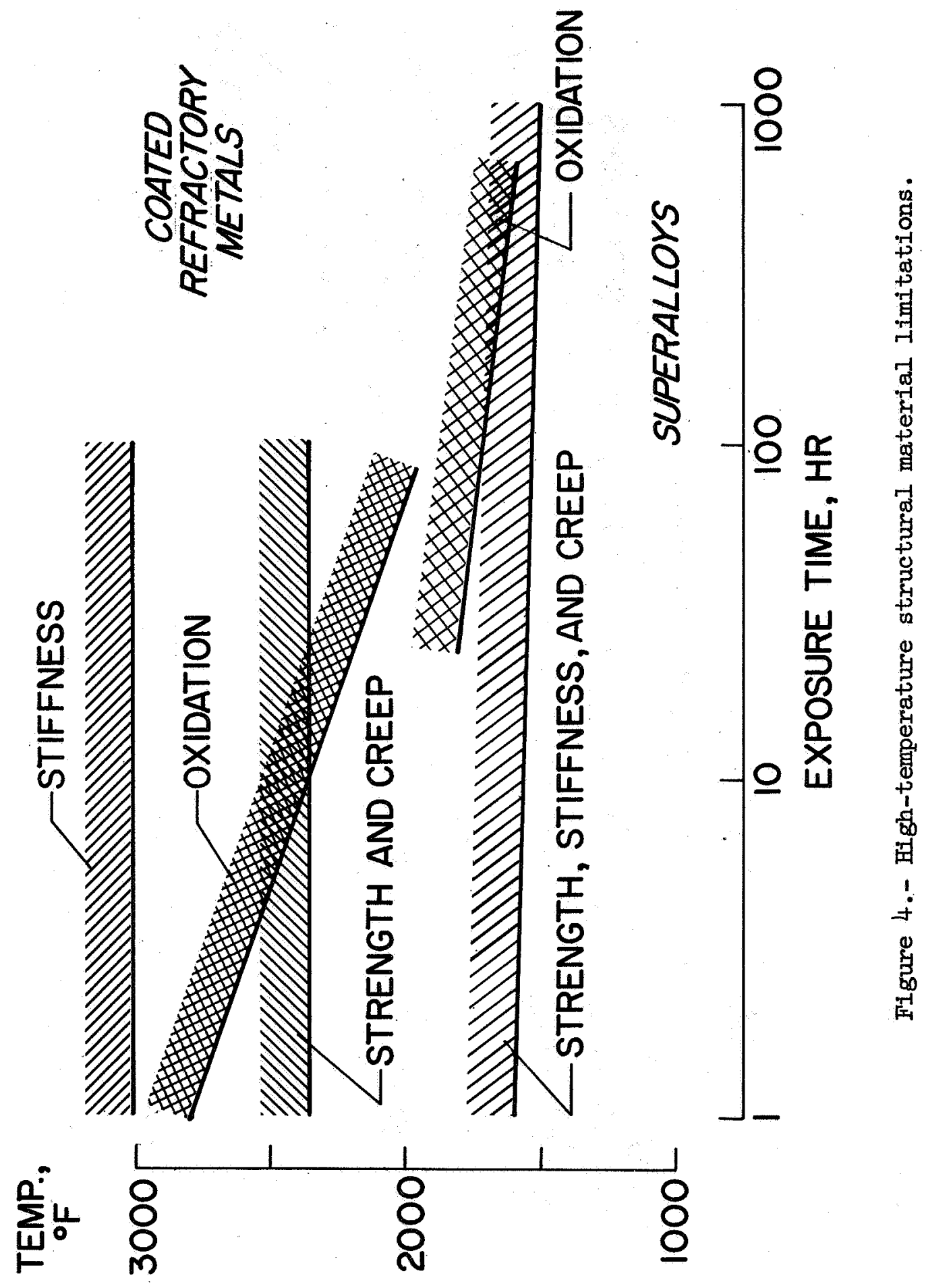




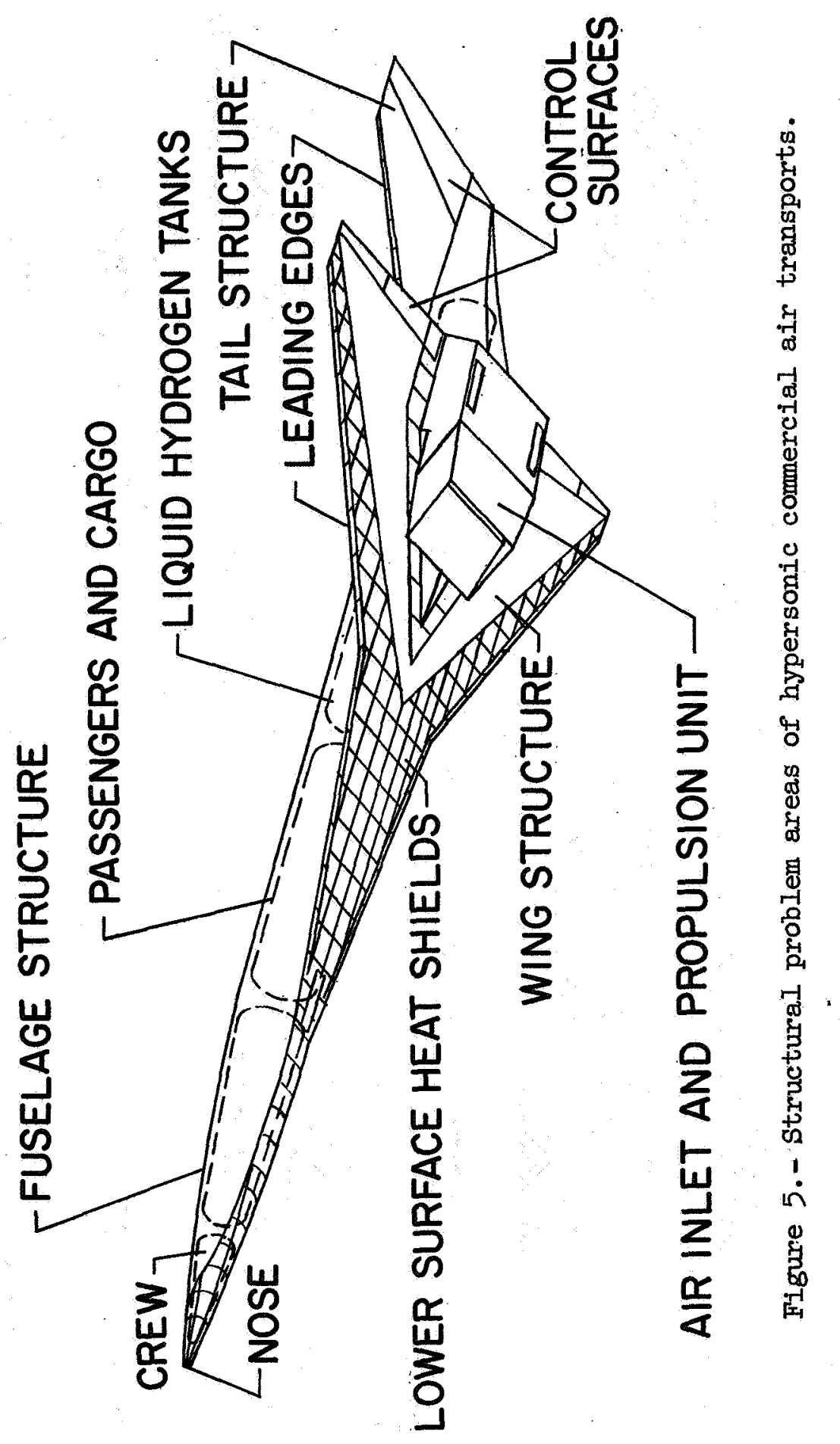



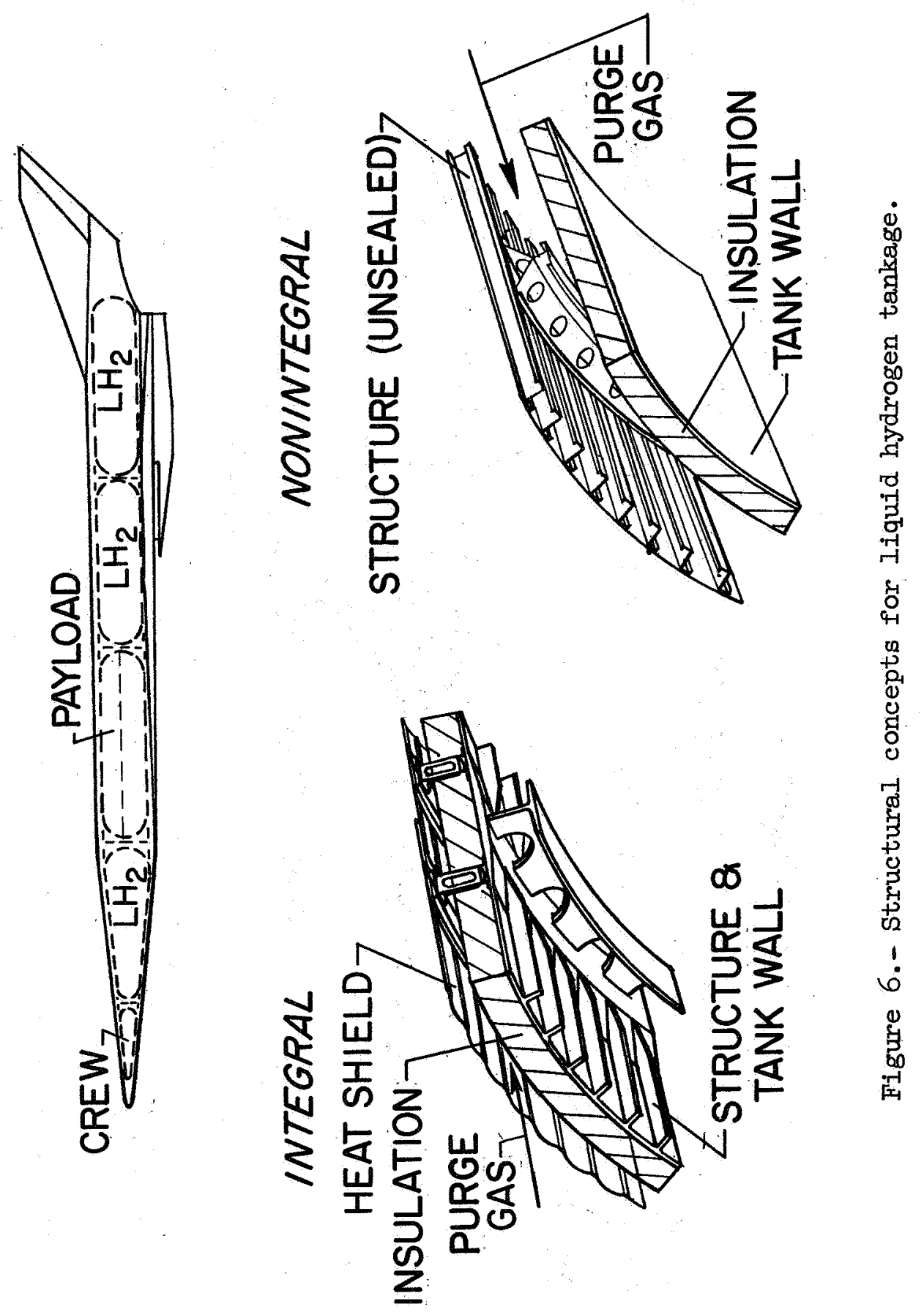


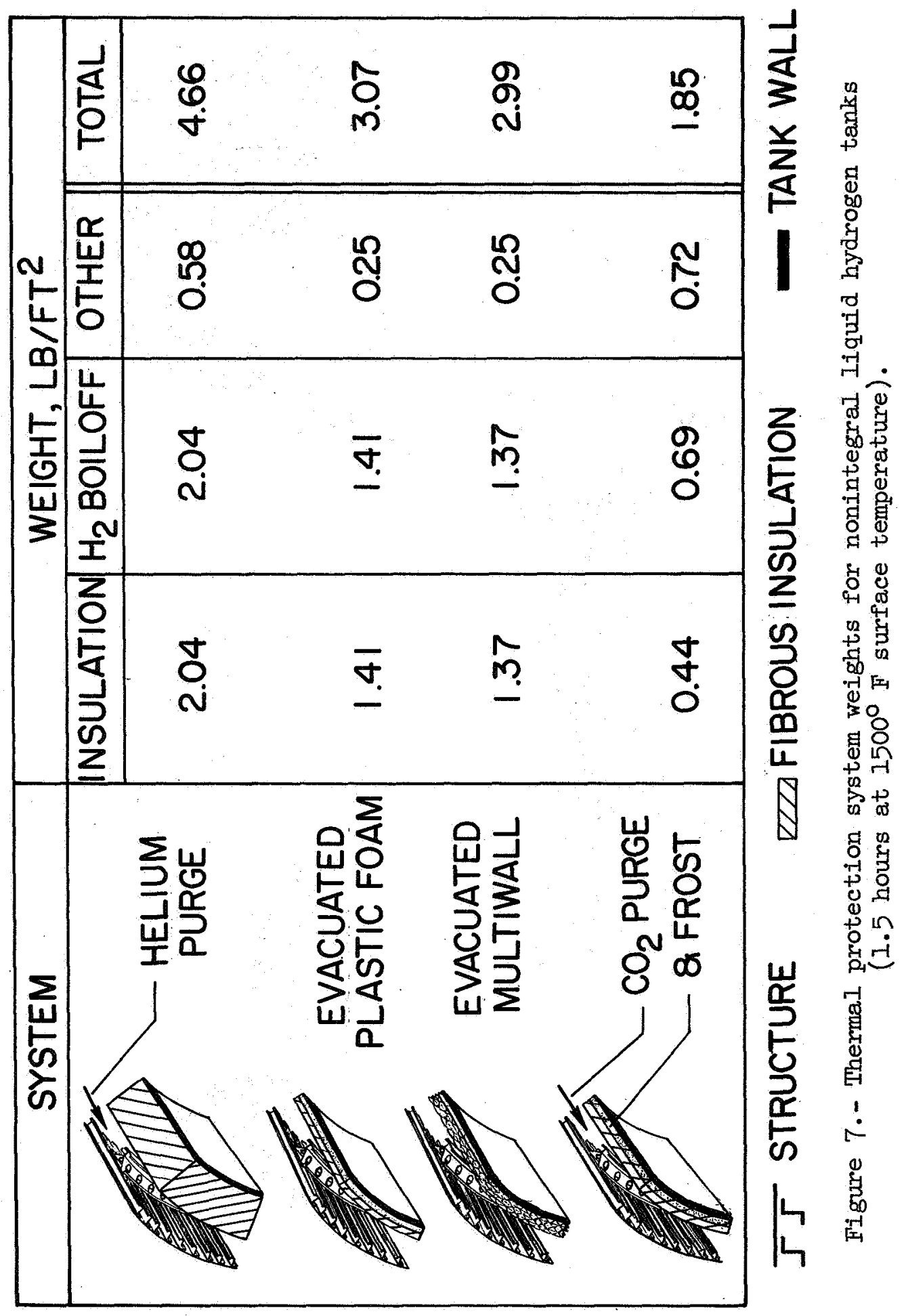




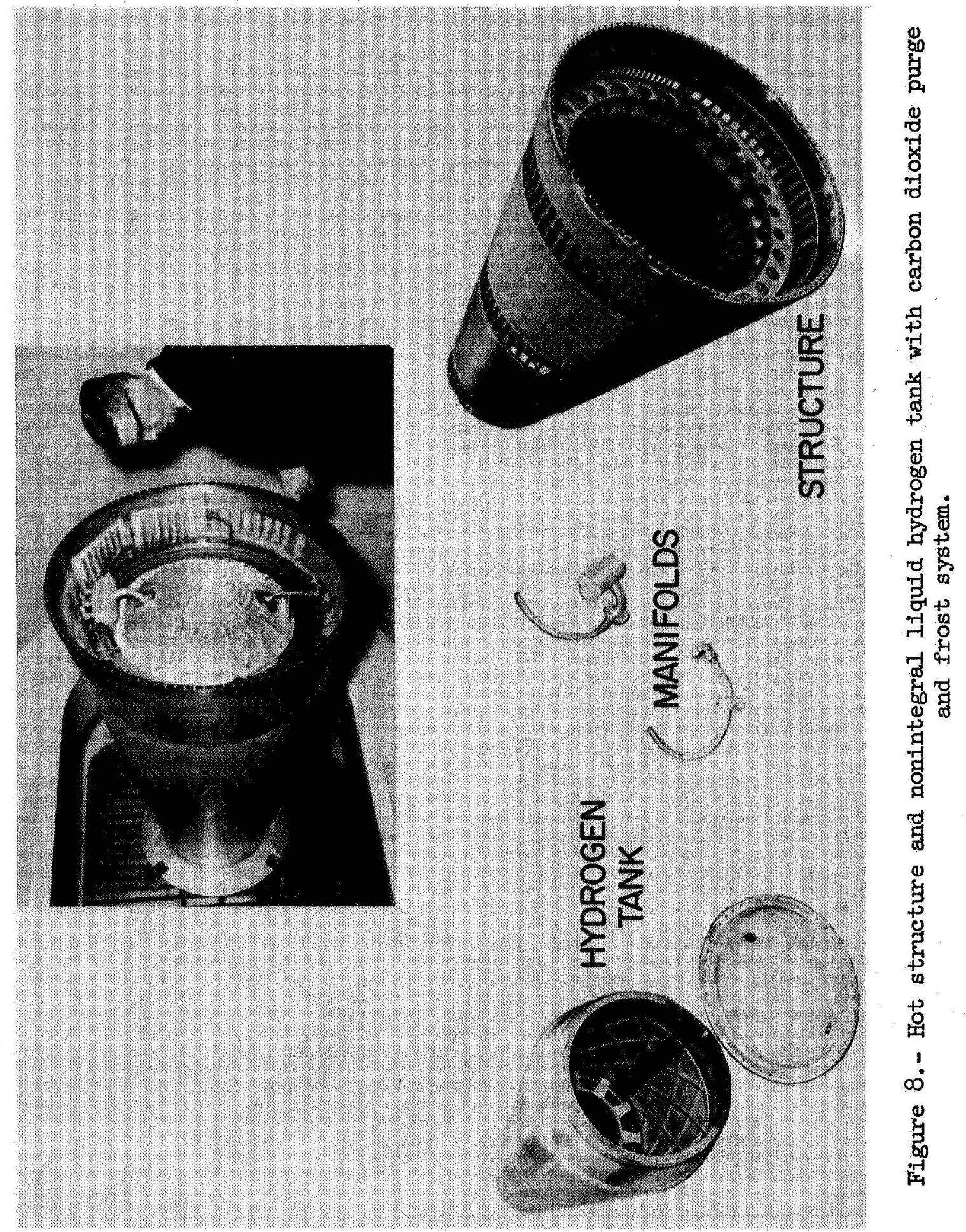




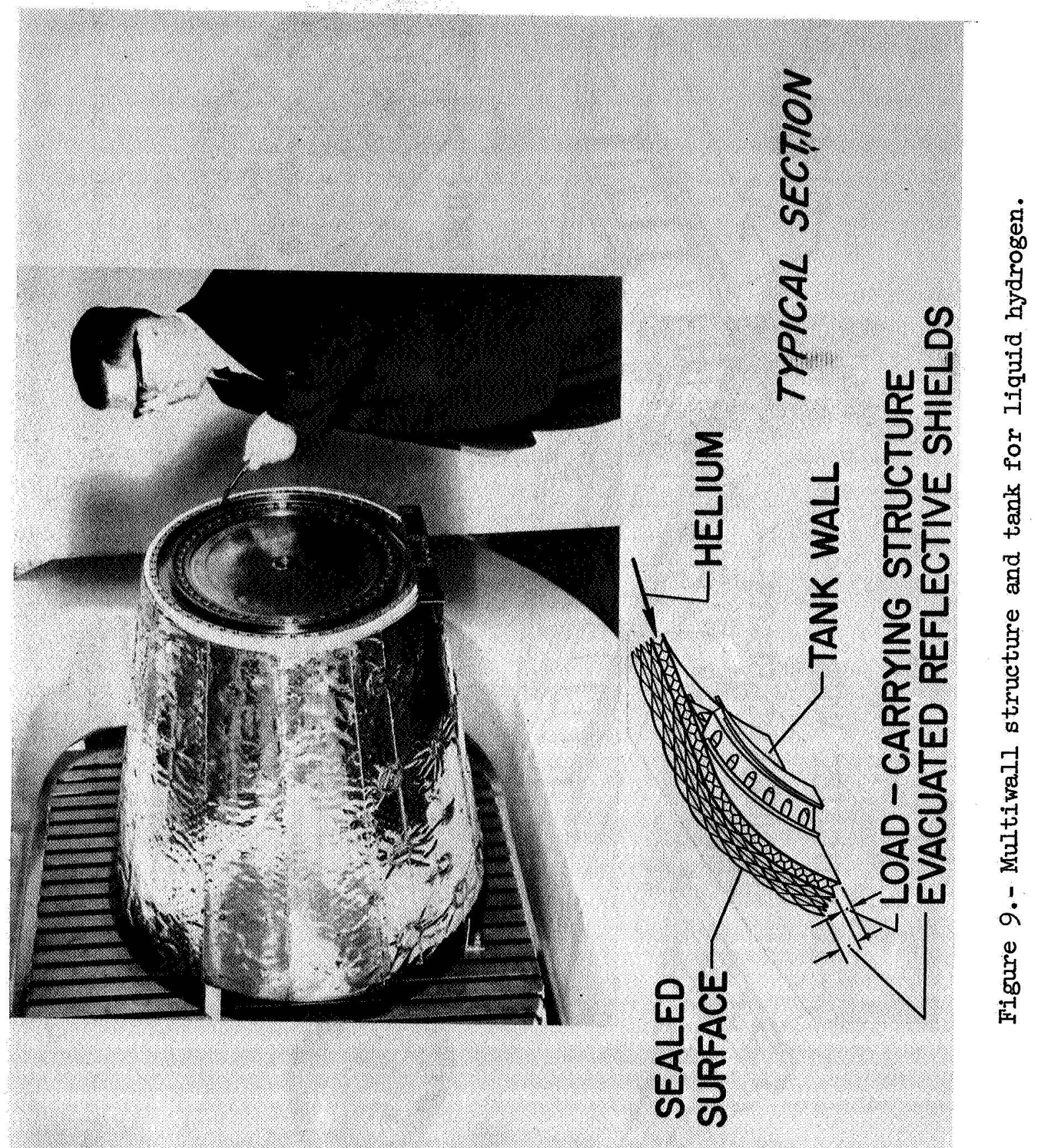




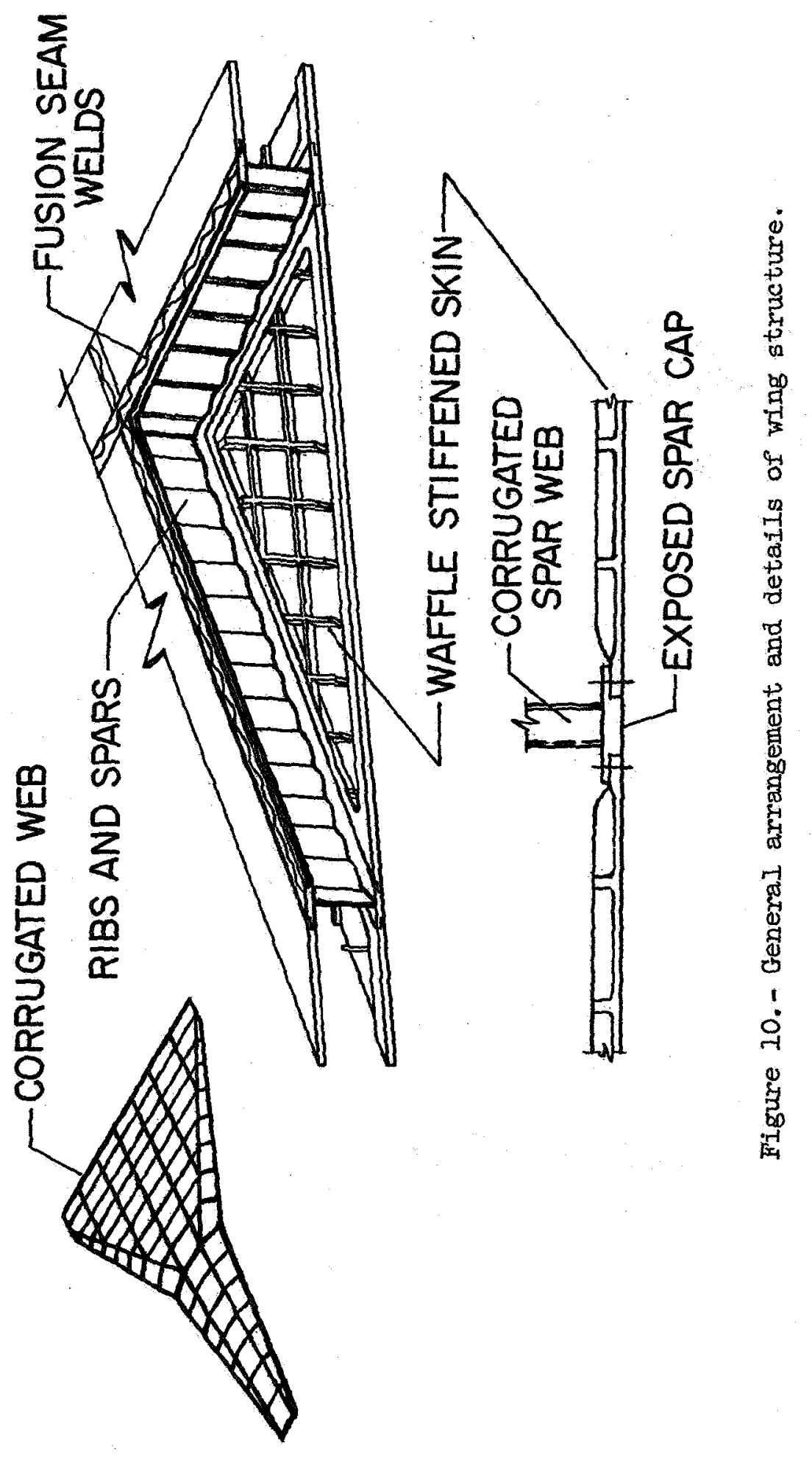




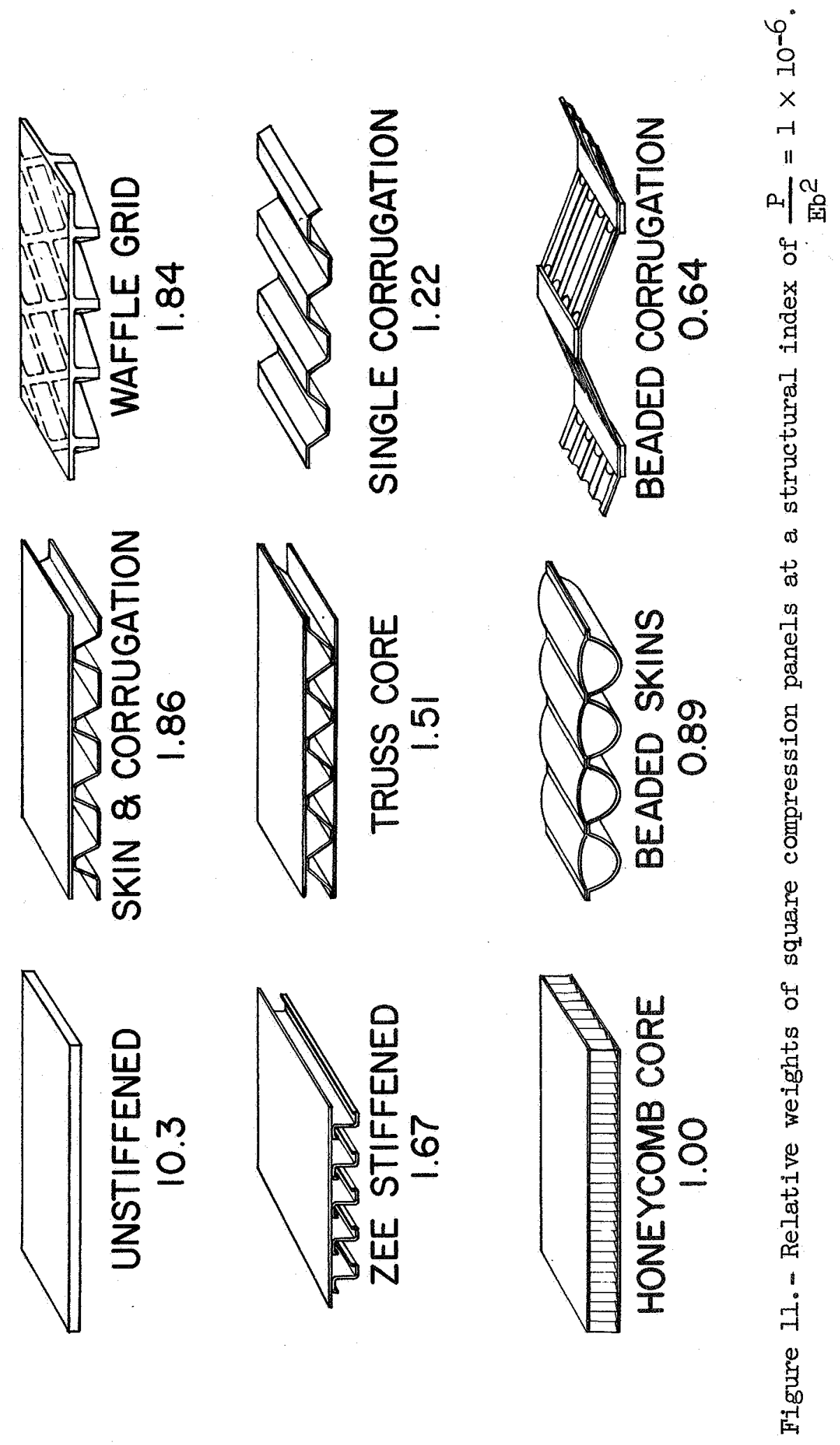




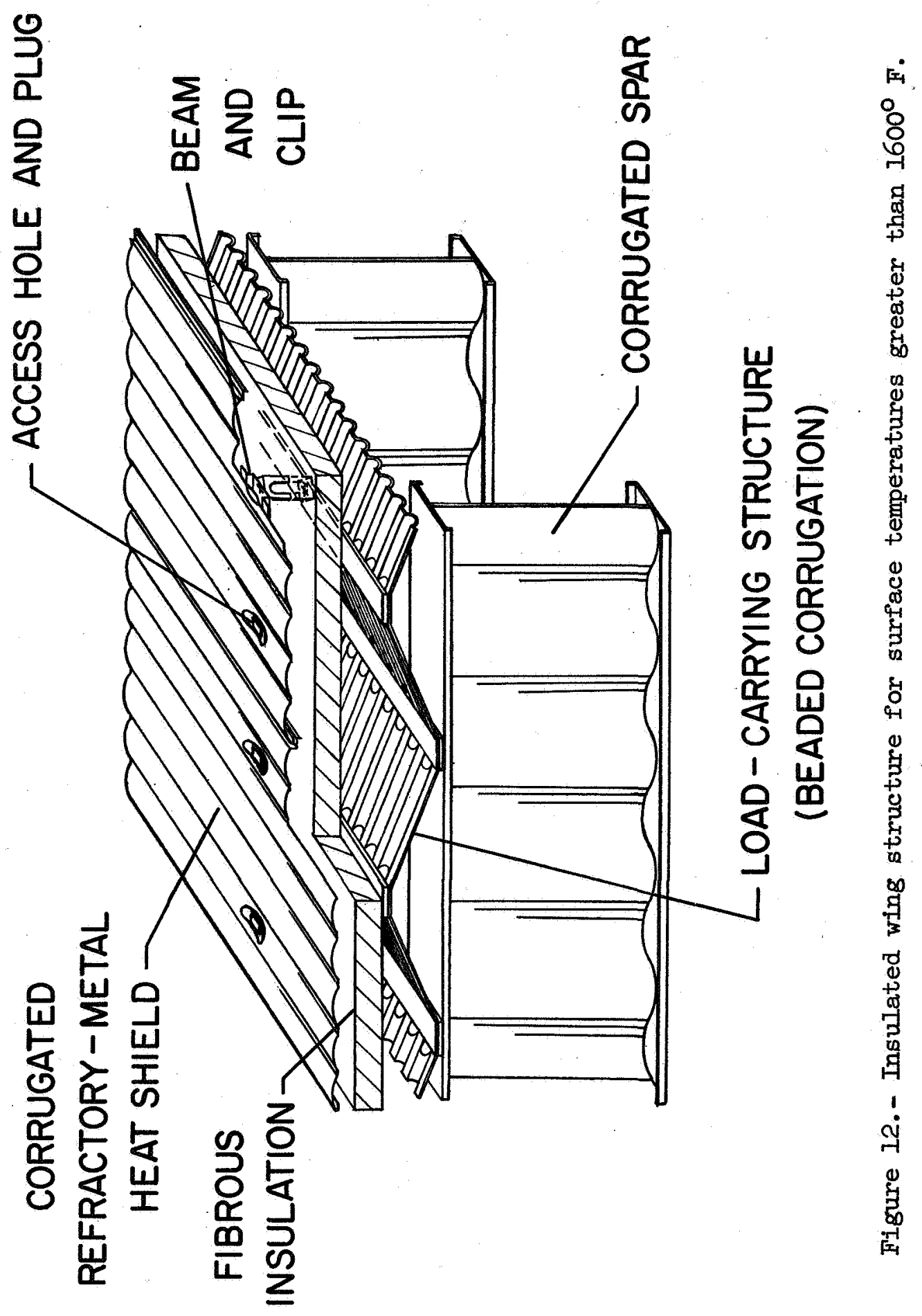




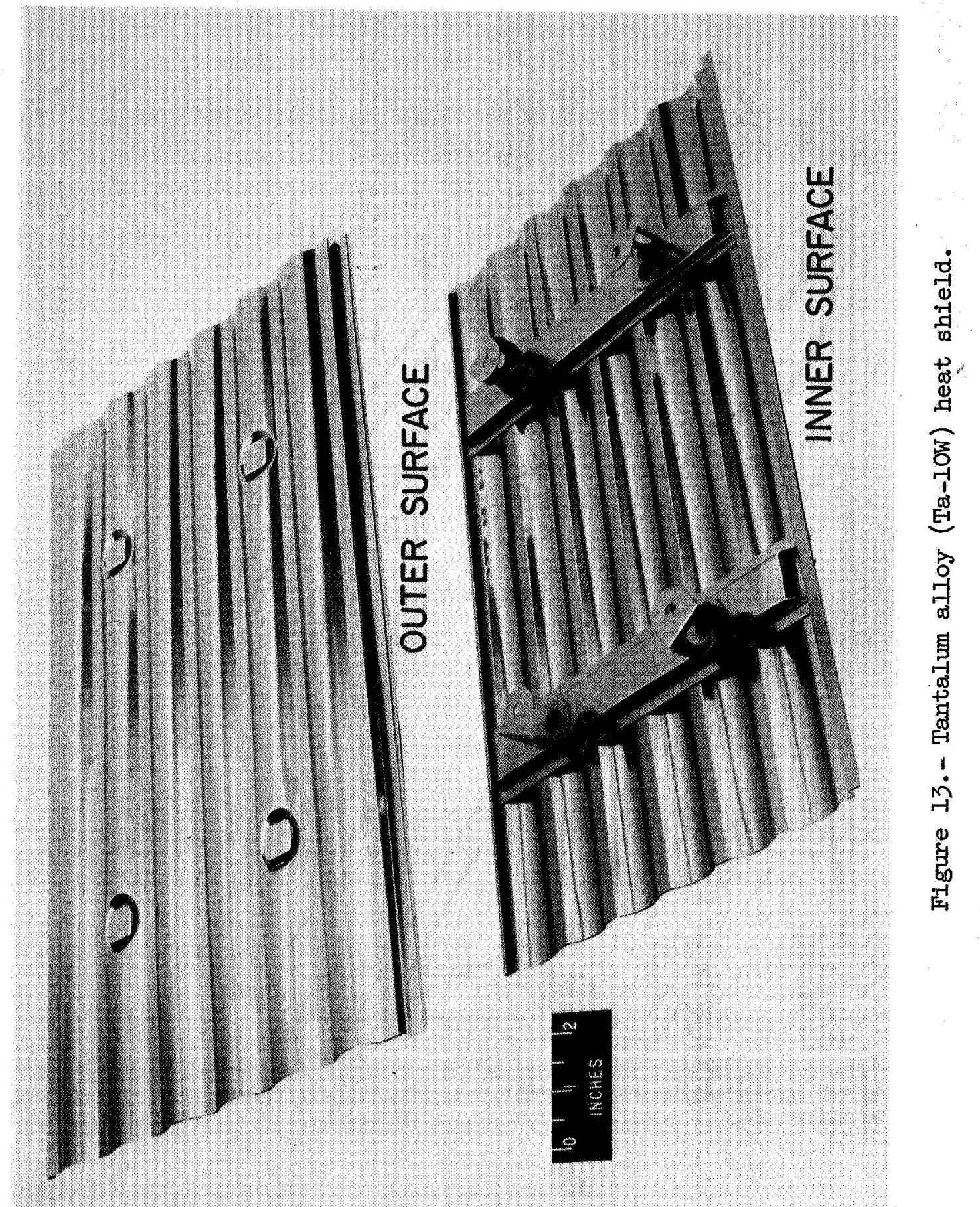




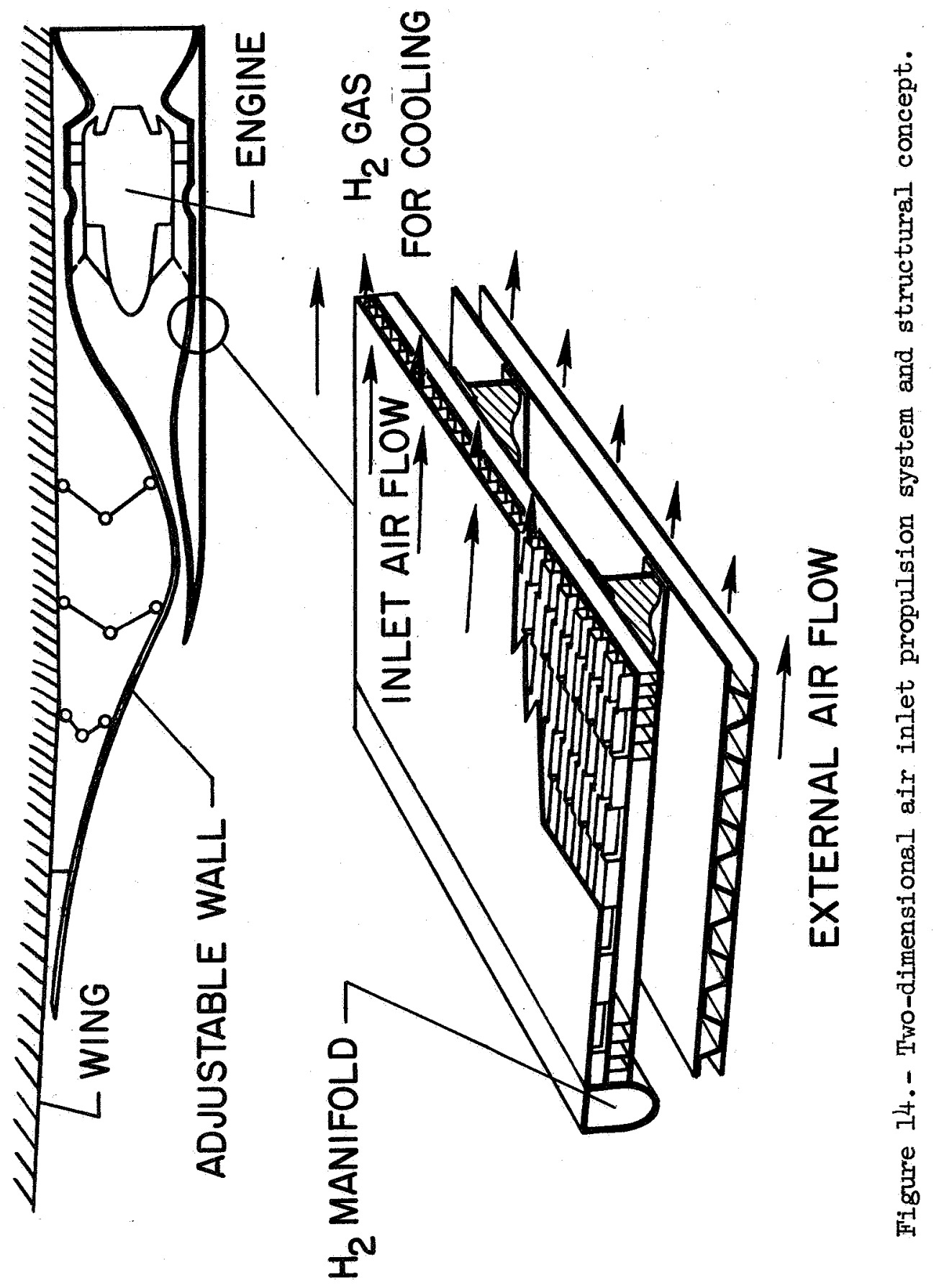



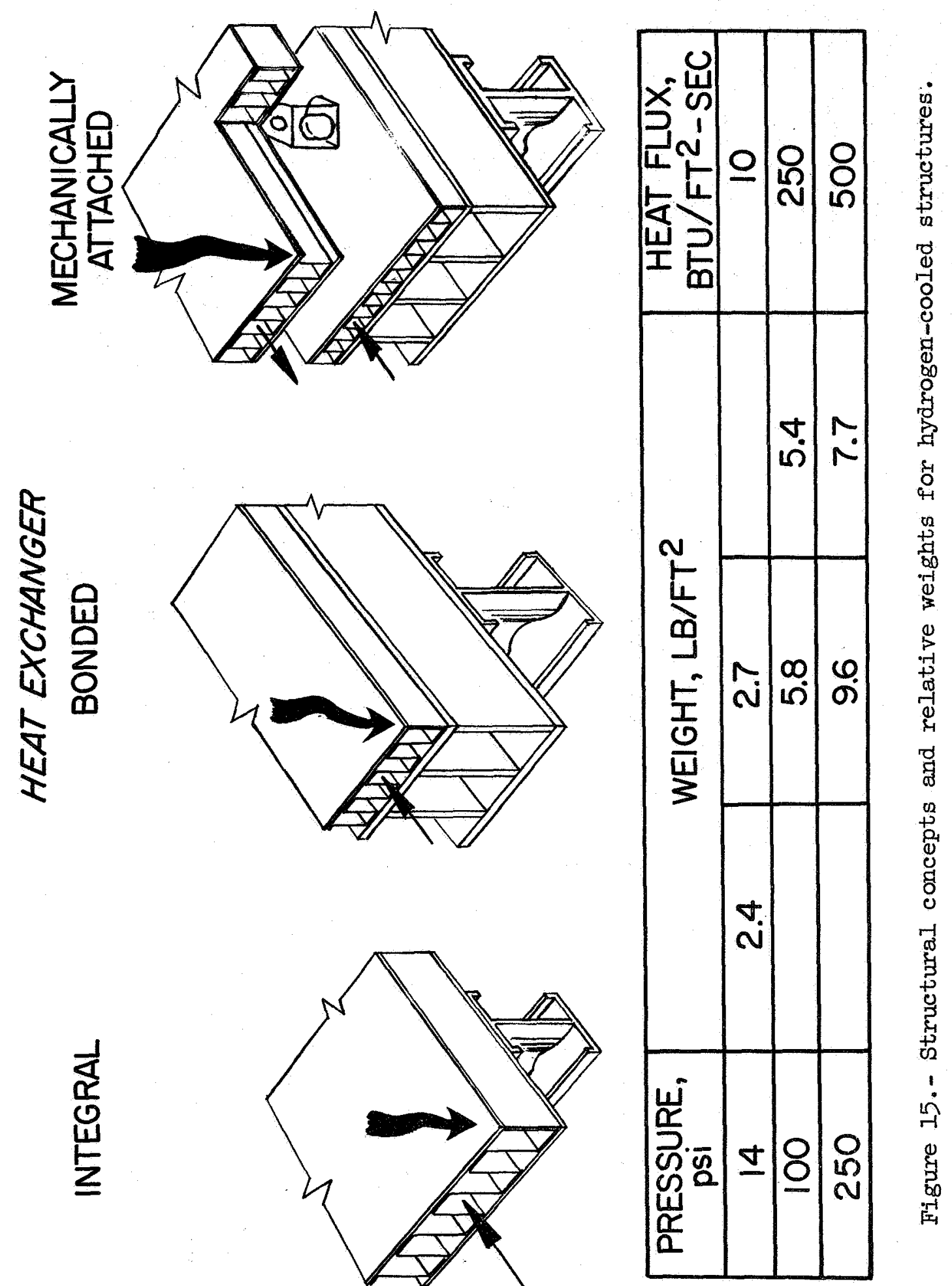

㕝

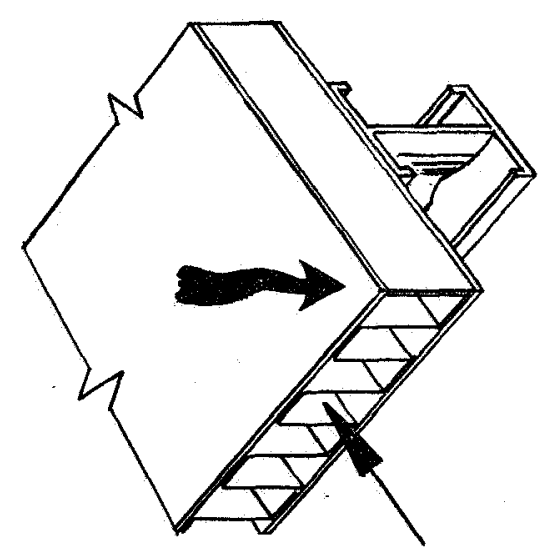




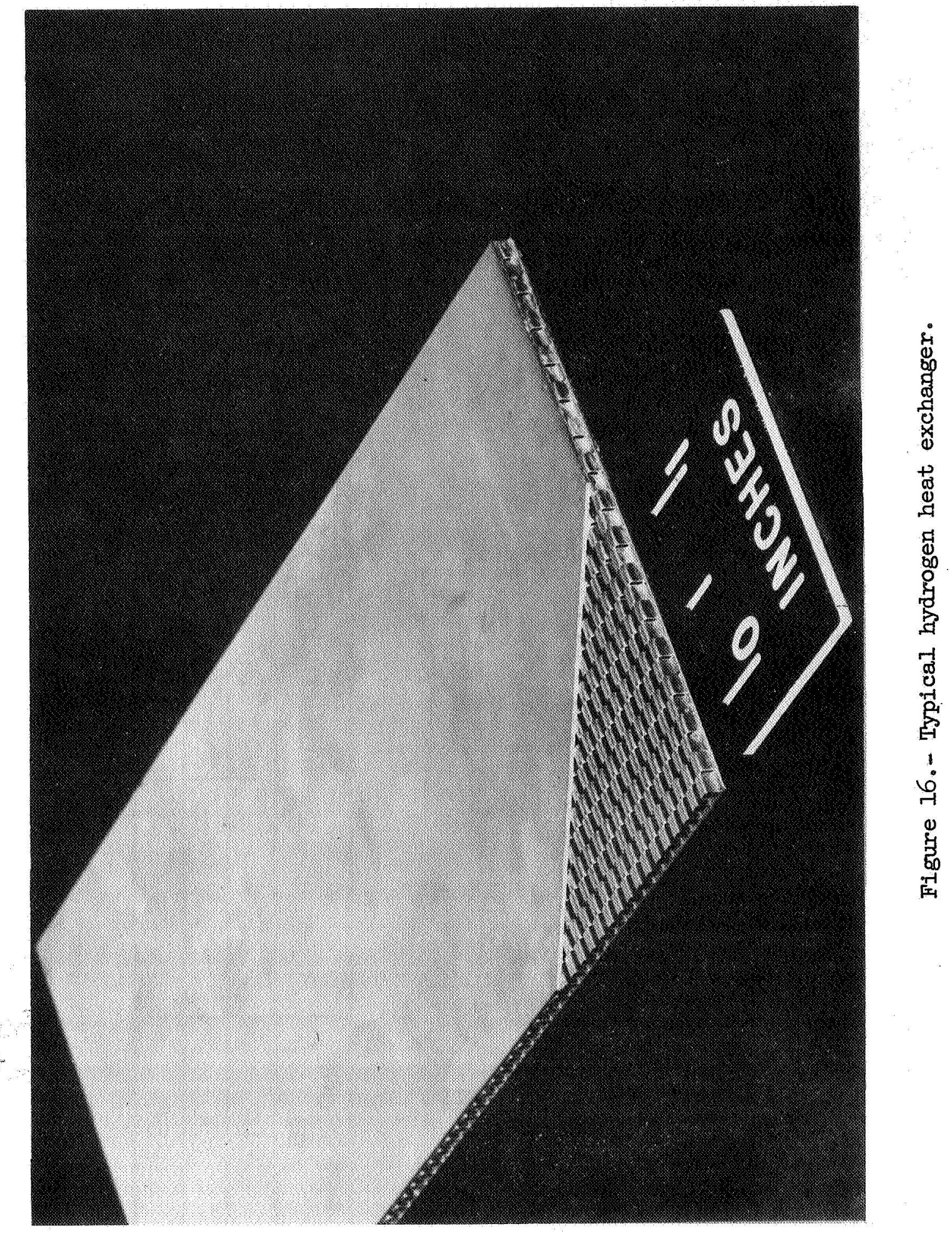

